\title{
The Many Paradoxes Of Control
}

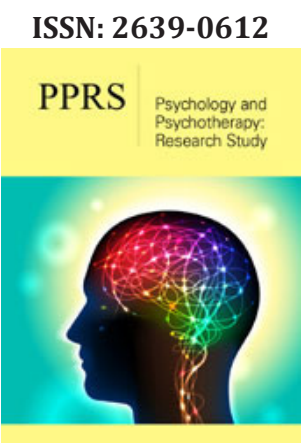

*Corresponding author: Torill Christine Lindstrøm, Department of Psychosocial Science, Norway

Submission: 悳 June 05, 2020

Published: 阷June 15, 2020

Volume 3 - Issue 5

How to cite this article: Torill Christine Lindstrøm. The Many Paradoxes of Control. Psychol Psychother Res Stud. 3(5).PPRS.000571.2020.

DOI: 10.31031/PPRS.2020.03.000571

Copyright@ Torill Christine L, This article is distributed under the terms of the Creative Commons Attribution 4.0 International License, which permits unrestricted use and redistribution provided that the original author and source are credited.

\author{
Torill Christine Lindstrøm* \\ Department of Psychosocial Science, Norway
}

\section{Opinion}

The word control has several meanings, direct, as well as indirect. It connotes even opposite phenomena. When I interviewed people about their associations to 'control', these are some of the first elements that came up: Safety. Control means that somebody takes care of everybody else's safety. Airplanes are constantly controlled, and so are the passengers, so that accidents and terrorist attack are avoided. Next was: Coercion. The passenger-controls that provide safety also imply a sometimes embarrassing opening of bags and body search. To be a person in charge of control, particularly in difficult and challenging situations, means to have positive positions of power, but also a position with severe responsibilities. To be controlled, can be humiliating and intimidating. That one spouse exerts control over the other, is generally regarded as negative, but for parents to have control over their little children is regarded as positive and responsible.

Personality-wise, some people are almost obsessed with having control. A diagnostic term for this is compulsive obsessive disorder. In colloquial language, we sometimes call another person (or oneself) a control-freak. These persons can be very annoying in private settings, with a compulsive tidying, and constant double-checking also because they tend to impose their behaviors on others. But we do want airplane-technicians, pilots, dentists, doctors and surgeons to be hyper-controlling and overzealous in doing things right and to have control over what they are doing. They are in charge of our destiny, at least some of it. We want them to be control-freaks!

Whereas a compulsive obsessive control-freak may suffer from an unconscious sense of insecurity, we tend to think of controlled persons as somebody who have control over their cognitions and emotions, are stable, reliable, and reasonably predictable. Having a healthy personality, in other words. Their behavior is structured; they can tolerate and continue to cope in situations of ambiguity and uncertainty. To be directed and advised by this kind of person, mean recognition of the positive quality of this controlled person's control. This is very different from the feeling of being involuntarily directed and controlled by somebody who has the authority to exert control, but not the competency. So, to be under others' control, can be relaxed or strained, safe or unsafe, restricting or liberating, necessary or unnecessary, boring and tedious but still good. But there are also other aspects of 'control', connected to being a patient.

In a longitudinal research project, we studied Norwegian breast-cancer patients' experiences over 9 years after their primary cancer surgery [1-5]. It was evident that the concept of 'control' was important for them on multiple levels. From feeling healthy with no symptoms, to receive the cancer diagnosis and be drawn into surgery and subsequent treatments (radiation, cytostatic treatments, etc.) meant a complete loss of control over their lives. From one day to the other, it was the cancer and the medial staff who took control. There was not a single area of these women's lives that was left unaffected by their cancertreatments. To be put on sick-leave, the following loneliness, to have a operation with ensuing problems (bleeding, liquids, swellings), pains, nausea, tiredness, lack of initiative, anxiety about the cancer-treatment trajectories and, last but not the least: death anxiety. For those with partners and families, they felt that their cancer affected the whole family's life. And, 
some of those who had to remove a breast felt that their femininity, attractiveness, and sex-life was affected.

Yet, these women were also lucky. Their cancer did not ruin their economy. Living in Norway, sick-leave compensation is automatic; health-care services are almost free. (Up to a certain amount (ca $\$ 200$ ) one pays parts of what each consultation costs, after that all is free for that year). Hospitalization is completely free, and so are the follow-ups, the cancer controls. Yet, the yearly cancer-controls were experienced as severely taxing and anxiety-provoking. Their, over the years, resumed feeling of being in control over their lives dwindled as they approached the hospital. An overwhelming loss-of-control-feeling engulfed them. The reasons are obvious. The hospital itself aroused memories of unpleasant surgery and treatments. In the hospital corridors and waiting-room these women were exposed to the frightening sight of other patients with severe disfigurements of faces and bodies, due to cancer. Their anxiety was rekindled: "Could this be me in some years? May the cancer come back? May I have a late relapse?" Loss of control!

Although the cancer controls, over so many years, are meant to give former breast-cancer patients a feeling of security and control, it obviously is "a double-edged sword": To be back at the hospital evokes bad memories, severe cancer-destinies are observed; and the result of the control is not immediately ready, so the women have to be "in limbo" for some time to wait for the results. Finally, to be summoned for controls even 9 years after their surgery, after they have been declared free of breast-cancer, is expected to provide a positive sense of control to these women. But: paradoxically: it actually also communicates that the medical staff is not $100 \%$ sure that the cancer could not recur, and that modern cancer treatment actually does not give the patients the complete control that they want. Control is indeed very paradoxical.

\section{References}

1. Sigrunn D, Torill CL, Kjell U (2010) Coping with breast cancer: Between diagnosis and surgery. Journal of Advanced Nursing 66: 149-158.

2. Sigrunn D, Torill Christine L, Gisk T, Kjell U (2011) Being in suspense: Women's experiences awaiting breast cancer surgery. Journal of Advanced Nursing 67: 1941-1951.

3. Sigrunn D, Torill Christine L, Kjell U (2016) I just have to move on. Women's coping experiences and reflections following their first year after primary breast cancer surgery. European Journal of Oncology Nursing 21: 205-211.

4. Sigrunn D, Torill Christine L, Sidsel E (2020) Cancer changed my life. Women's experiences 1 and 9 years after primary breast cancer surgery. Nordisk Sygepleieforskning 10: 20-33.

5. Sigrunn D, Torill Christine L, Sidsel E (2020) I have both lost and gained. Norwegian survivors experiences of coping 9 years after primary breast cancer surgery. Cancer Nursing 43(1): 30-37. 